\title{
The U.S. Treasury yield curve: 1961 to the present ${ }^{\text {t }}$
}

\author{
Refet S. Gürkaynak ${ }^{\mathrm{a}}$, Brian Sack ${ }^{\mathrm{b}}$, Jonathan H. Wright ${ }^{\mathrm{c}, *}$ \\ a Department of Economics, Bilkent University, 06800 Ankara, Turkey and CEPR, London \\ ${ }^{\mathrm{b}}$ Macroeconomic Advisers, LLC, Washington, DC 20006, USA \\ ${ }^{\mathrm{c}}$ Federal Reserve Board, Washington, DC 20551, USA
}

Received 2 November 2006; received in revised form 25 June 2007; accepted 26 June 2007

Available online 6 July 2007

\begin{abstract}
The discount function, which determines the value of all future nominal payments, is the most basic building block of finance and is usually inferred from the Treasury yield curve. It is therefore surprising that researchers and practitioners do not have available to them a long history of highfrequency yield curve estimates. This paper fills that void by making public the Treasury yield curve estimates of the Federal Reserve Board at a daily frequency from 1961 to the present. We use a wellknown and simple smoothing method that is shown to fit the data very well. The resulting estimates can be used to compute yields or forward rates for any horizon. We hope that the data, which are posted on the website http://www.federalreserve.gov/pubs/feds/2006 and which will be updated quarterly, will provide a benchmark yield curve that will be useful to applied economists.
\end{abstract}

(C) 2007 Elsevier B.V. All rights reserved.

JEL classification: G12; E43

Keywords: Yield curve; Treasury market; On the run premia; High-frequency data

\footnotetext{
${ }^{2}$ We are grateful to Oliver Levine for superlative research assistance and to Bob King, Brian Madigan, Vincent Reinhart, Jennifer Roush and an anonymous referee for helpful comments. All remaining errors are our own. All of the authors were involved in yield curve estimation at the Federal Reserve Board when working at that institution. The views expressed in this paper are solely the responsibility of the authors and should not be interpreted as reflecting the views of the Board of Governors of the Federal Reserve System or of any other employee of the Federal Reserve System.

${ }^{*}$ Corresponding author. Tel.: + 12024523696 ; fax: + 12022634843.

E-mail addresses: refet@bilkent.edu.tr (R.S. Gürkaynak), sack@macroadvisers.com (B. Sack), jonathan. h.wright@frb.gov (J.H. Wright).
} 


\section{Introduction}

Interest rates are one of the basic ingredients of applied work in macroeconomics and finance. Having a long time series of properly measured high-frequency yield curves will therefore facilitate research in these areas. Towards that end, this paper fits a yield curve to off-the-run Treasury notes and bonds at the daily frequency for the entire maturity range spanned by outstanding Treasury securities, from 1961 to 2006. The resulting yield curve can be expressed in terms of zero-coupon yields, par yields, instantaneous forward rates, or $n \times m$ forward rates (that is, the $m$-year rate beginning $n$ years ahead) for any $n$ and $m$.

Several authors have produced time series estimates of U.S. Treasury yield curves. Perhaps the most commonly used among these are the Fama-Bliss (1987) yields. Commonly available Fama-Bliss yields are month-end measures of yield curves going out to five years in maturity. The yield curve estimates that we present more information than the Fama-Bliss yields in three ways. First, we provide daily estimates, facilitating highfrequency studies. Second, we present estimates going out to the longest available maturity-for example, we provide more than 35 years of 10-year yields. Lastly, the estimates presented in this paper will be updated quarterly, keeping the data current.

Section 2 of the paper briefly reviews the fundamental concepts of the yield curve. Section 3 describes the specific methodology that we employ to estimate the yield curve, and Section 4 discusses our data and some of the details of the estimation. Section 5 shows the results of our estimation, including an assessment of the fit of the curve, and Section 6 demonstrates how the estimated yield curve can be used to calculate the yield on "synthetic" Treasury securities with any desired maturity date and coupon rate. As an application of this approach, we create a synthetic off-the-run Treasury security that exactly replicates the payments of the on-the-run 10-year Treasury note, allowing us accurately to measure the liquidity premium on that particular issue. Section 7 concludes. The data are posted as an appendix to the paper on the FEDS website.

\section{Basic definitions}

This section reviews the fundamental concepts of the yield curve, including the necessary "bond math" that will be used in the subsequent discussion. ${ }^{1}$

\subsection{The discount function and zero-coupon yields}

The starting point for pricing any fixed-income asset is the discount function, or the price of a zero-coupon bond. This represents the value today to an investor of a $\$ 1$ nominal payment $n$ years hence. We denote this as $d_{t}(n)$. The continuously compounded yield on this zero-coupon bond can be written as

$$
y_{t}(n)=-\ln \left(d_{t}(n)\right) / n \text {. }
$$

Although the continuously compounded basis may be the simplest way to express yields, a widely used convention is to instead express yields on a "coupon-equivalent" or

\footnotetext{
${ }^{1}$ The concepts and algebra presented here are a shortened version of the detailed exposition available in the working paper form of this paper, Gürkaynak et al. (2006).
} 
"bond-equivalent" basis, in which case the compounding is assumed to be semi-annual instead of continuous. The coupon-equivalent yield is $y_{t}^{\mathrm{ce}}=2 \exp \left(1+y_{t} / 2\right)$.

\subsection{The par-yield curve}

Given the discount function, it is straightforward to price any coupon-bearing bond by summing the value of its individual payments. For example, the price of a coupon-bearing bond that matures in exactly $n$ years (paying $\$ 1$ ) is as follows:

$$
P_{t}(n)=\sum_{i=1}^{2 n}(c / 2) d_{t}(i / 2)+d_{t}(n),
$$

where $c / 2$ is the semi-annual coupon payment on the security-that is, it has a stated annual coupon rate of $c .^{2}$ Of course, for coupon-bearing bonds, the yield will depend on the coupon rates that are assumed.

One popular way among market participants to express the yields on coupon-bearing bonds is through the concept of par yields. A par yield for a particular maturity is the coupon rate at which a security with that maturity would trade at par (and hence have a coupon-equivalent yield equal to that coupon rate). The yield can be determined from an equation similar to (2), only setting the price of the security equal to $\$ 1$. The par yield is then given $b^{3}$

$$
y_{t}^{p}(n)=\frac{2\left(1-d_{t}(n)\right)}{\sum_{i=1}^{2 n} d_{t}(i / 2)} .
$$

Zero-coupon yields are a mathematically simpler and more fundamental concept than par yields. But an advantage of expressing the yield curve in terms of par yields is that financial market participants typically quote yields on coupon-bearing bonds and use the par yields.

\subsection{Forward rates}

The yield curve can also be expressed in terms of forward rates rather than yields. A forward rate is the yield that an investor would agree to today to make an investment over a specified period in the future-for $m$-years beginning $n$ years hence. These forward rates can be synthesized from the yield curve. Without any coupon payments, the continuously compounded return on that investment is given by the following formula:

$$
f_{t}(n, m)=-\frac{1}{m} \ln \left(\frac{d_{t}(n+m)}{d_{t}(n)}\right)=\frac{1}{m}\left((n+m) y_{t}(n+m)-n y_{t}(n)\right) .
$$

Taking the limit of (4) as $m$ goes to zero gives the instantaneous forward rate $n$ years ahead, which is the instantaneous return for a future date that an investor

\footnotetext{
${ }^{2}$ Because the bond matures in exactly $n$ years, it is assumed to make its coupon payment today. Thus, the endof-day price of the bond includes no accrued interest.

${ }^{3}$ For simplicity, this formula again assumes that a coupon payment has just been made and the next coupon is a full coupon period away, so that there is no accrued interest.
} 
would demand today:

$$
f_{t}(n, 0)=\lim _{m \rightarrow 0} f_{t}(n, m)=y_{t}(n)+n y_{t}^{\prime}(n)=-\frac{\partial}{\partial n} \ln \left(d_{t}(n)\right) .
$$

Notice that (5) implies that the yield curve is upward (downward) sloping whenever the instantaneous forward rate is above (below) the zero-coupon yield at a given maturity.

One can think of a term investment today as a string of forward rate agreements over the horizon of the investment, and the yield therefore equals the average of those forward rates. Specifically, from Eq. (5), $\ln \left(d_{t}(n)\right)=-\int_{0}^{n} f_{t}(x, 0) \mathrm{d} x$, and so, from Eq. (1), the $n$-period zero-coupon yield (expressed on a continuously compounded basis) is given by

$$
y_{t}(n)=\frac{1}{n} \int_{0}^{n} f_{t}(x, 0) \mathrm{d} x .
$$

By using forward rates, we can summarize the yield curve in some potentially more informative ways. For example, the 10-year Treasury yield can be decomposed into 10 oneyear forward rates over that 10 -year horizon. Near-term forward rates tend to be affected by monetary policy expectations and hence cyclical variables, while longer-term forward rates are instead determined by factors seen as more persistent or by changes in risk preferences. The 10-year yield meshes these two types of influences together, whereas it may be easier to interpret that yield when one considers the near-term and distant forward rates separately.

\subsection{Duration and convexity}

We conclude this section by introducing two key yield curve concepts: duration and convexity. Much of the value of a coupon-bearing security comes from coupon payments, so the effective time that investors must wait to be repaid is shorter than the maturity of the bond. The Macaulay duration of a bond is a weighted average of the time that the investor must wait to receive the cash flows on a coupon-bearing bond (in years):

$$
D=\frac{1}{P_{t}(n)}\left[\sum_{i=1}^{2 n} \frac{i}{2} \frac{c}{2} d_{t}(i / 2)+n d_{t}(n)\right]
$$

For a given maturity, the higher the coupon rate is, the shorter the duration. The modified duration of a bond, $D_{\text {MOD }}$, is defined as the Macaulay duration divided by one plus the yield on the bond (assuming semi-annual compounding):

$$
D_{\mathrm{MOD}}=\frac{D}{1+y^{c e} / 2} \text {. }
$$

It can be shown that the derivative of the log price of a bond with respect to its yield is simply $-D_{\text {MOD }}$. Thus, modified duration provides the sensitivity (in percent) of the value of a bond to small changes in its yield. This first-order approximation to the relationship between changes in the log price of a bond and changes in yield is, however, accurate only for small changes in yield because the relationship between prices and yields is nonlinear. Convexity captures this nonlinearity. To a second-order approximation, the change in the $\log$ price of the bond is given by

$$
\mathrm{d} \log (P)=-D_{\mathrm{MOD}} \mathrm{d} y+\frac{1}{2} \kappa(\mathrm{d} y)^{2},
$$


where $\kappa=(1 / P) \mathrm{d}^{2} P / \mathrm{d} y^{2}$ is the convexity of the bond. Convexity means that the capital loss from a rise in interest rates will be smaller than the capital gain from a fall in interest rates. This Jensen's inequality effect is priced, and so convexity tends to pull down longerterm yields and forward rates, giving the yield curve a hump shape at the longest maturities that is discussed further below.

\section{Yield curve estimation}

If the Treasury issued a full spectrum of zero-coupon securities every day, then we could simply observe the yield curve and would have a complete set of the yields and forward rates. Unfortunately, this is not the case. The Treasury has instead issued a limited number of securities with different maturities and coupons. Each of these can be viewed as a basket of zero-coupon securities: one for each coupon date and one for the final principal payment. However, we do not have securities at all maturities and so cannot simply solve for implied zero-coupon yields. Instead, we must infer what the yields would be across the maturity spectrum from the prices of existing coupon-bearing securities. This is what constitutes yield curve estimation.

In embarking on this exercise, one is immediately confronted by the question of how much flexibility to allow in the yield curve. The observed prices of Treasury securities surely do not all exactly reflect the same underlying discount function: idiosyncratic issues arise for specific securities, such as liquidity premia, hedging demand, demand for deliverability into future contracts, or repo market specialness. It is necessary to impose some structure on the yield curve to smooth through some of this idiosyncratic variation. However, one can choose different methods that vary in terms of how much flexibility is allowed. A very flexible yield curve would price securities correctly, but do so with considerable variability in the forward rates. Or, one could impose more smoothness on the shape of the forward rates while sacrificing some of the fit of the curve. The more flexible approaches tend to be splinebased methods that involve a large number of estimated parameters (Fisher et al., 1995; Waggoner, 1997; McCulloch, 1975, 1990), while the more rigid methods tend to be parametric forms that involve a smaller number of parameters.

The choice in this dimension depends on the purpose that the yield curve is intended to serve. A trader looking for small pricing anomalies may be very concerned with how a specific security is priced relative to those securities immediately around it. By contrast, a macroeconomist will likely be more interested in understanding the fundamental determinants of the yield curve and may wish to use a more rigid yield curve that smooths through such variation. Our primary purpose in estimating the yield curve is to understand its fundamental determinants such as macroeconomic conditions, monetary policy prospects, perceived risks, and investors' risk preferences. Considering this purpose, we will employ a parametric yield curve specification. As will be seen below, this specification will allow for very rich shapes of the forward curve while largely ruling out variation resulting from any anomalous pricing of a small number of securities at a given maturity.

Our approach follows the extension by Svensson (1994) of the functional form that was initially proposed by Nelson and Siegel (1987). This assumes that the forward rates are governed by six parameters according to the following functional form:

$$
f_{t}(n, 0)=\beta_{0}+\beta_{1} \exp \left(-n / \tau_{1}\right)+\beta_{2}\left(n / \tau_{1}\right) \exp \left(-n / \tau_{1}\right)+\beta_{3}\left(n / \tau_{2}\right) \exp \left(-n / \tau_{2}\right) .
$$


We refer to this as the NSS (Nelson-Siegel-Svensson) functional form. With this function, instantaneous forward rates begin at horizon zero at the level $\beta_{0}+\beta_{1}$ and eventually asymptote to the level $\beta_{0}$. Two "humps" are allowed for in the forward curve, the locations of which are determined by the parameters $\tau_{1}$ and $\tau_{2}$. The original Nelson-Siegel functional form is a special case of this in which $\beta_{3}=0$, which therefore admits only one "hump" in the forward curve. However, as we will see below, the yield curve often needs two humps, one at short maturities associated with monetary policy expectations and another at long maturities, to capture convexity effects.

Thus, for a given set of parameters, the NSS specification characterizes the forward curve and hence the zero-coupon yield curve and discount function at all maturities, using the formulas given in the previous section. The discount function can then be used to price all outstanding Treasury securities with specific coupon rates and maturity dates. In estimating the yield curve, we choose the parameters to minimize the weighted sum of the squared deviations between the actual prices of Treasury securities and the predicted prices. The weights are the inverse of the durations of each individual security. ${ }^{4}$

\section{Data and estimation issues}

Our underlying quotes on Treasury securities come from two primary sources. For the period from 14 June 1961 to the end of November 1987, we rely on the CRSP daily Treasury file, which provides end-of-day quotes on all outstanding Treasury securities. Since December 1987, we use Treasury quotes provided by the Federal Reserve Bank of New York (FRBNY), which is a proprietary database constructed from several sources of market information. ${ }^{5}$

An immediate issue that arises is determining the set of securities to be included in the estimation. The Treasury securities outstanding at any point in time can differ in many dimensions, including their liquidity and their callable features. Our goal is to use a set of securities that are similar in terms of their liquidity and that do not have special features (such as being callable) that would affect their prices. In other words, we would ideally have securities that only differ in terms of their coupons and maturities.

To that end, we include in the estimation all outstanding Treasury notes and bonds, with the following exceptions:

(i) We exclude securities with option-like features, including callable and flower bonds. ${ }^{6}$

(ii) We exclude all securities with less than three months to maturity, since the yields on these securities often seem to behave oddly. This behavior may partly reflect the lack of

\footnotetext{
${ }^{4}$ Because of the nonlinear relationship between bond prices and yields, minimizing the square pricing errors will not produce the best fit in yields. Weighting prices by inverse durations, to a first approximation, converts the pricing errors into yield fitting errors, given the definition of duration in Section 2.4. Fitting inverse-durationweighted prices rather than yields is preferable because it is computationally about 200 times faster. This is because converting the fitted price of a bond into its yield involves numerical solution of a nonlinear equation, which must be done for every bond at every iteration of the optimization algorithm, if we minimize the sum of squared yield-fitting errors. As we estimate yield curves for more than 11,000 days, computational efficiency matters. By directly fitting yields for a random selection of days we verified that the approximation using inverseduration-weighted prices generates yield curve parameters that are virtually identical to parameters obtained from fitting yields.

${ }^{5} \mathrm{We}$ are not permitted to release either the underlying CRSP data or the FRBNY data.

${ }^{6}$ Flower bonds were securities with low coupons that could be redeemed at par for the payment of estate taxes.
} 
liquidity for those issues and segmented demand for short-term securities by money market funds and other short-term investors.

(iii) We also exclude all Treasury bills out of concern about segmented markets. Duffee (1996) showed that bill rates are often disconnected from the rest of the Treasury yield curve.

(iv) We begin to exclude 20-year bonds in 1996, because those securities often appeared cheap relative to 10 -year notes with comparable duration. This cheapness could reflect their lower liquidity or the fact that their high coupon rates made them unattractive to hold for tax-related reasons. ${ }^{7}$

(v) We exclude the two most recently issued securities with maturities of two, three, four, five, seven, 10, 20, and 30 years for securities issued in 1980 or later. These are the "on-therun" and "first off-the-run" issues that often trade at a premium to other Treasury securities, owing to their greater liquidity and their frequent specialness in the repo market. ${ }^{8}$ Earlier in the sample, the concept of an on-the-run issue was not well defined, since the Treasury did not conduct regular auctions and the repo market was not well developed (Garbade, 2004). Our cut-off point for excluding on-the-run and first off-therun issues is somewhat arbitrary but is a conservative choice (in the sense of potentially erring on the side of being too early).

(vi) Other issues that we judgmentally exclude on an ad hoc basis.

These restrictions imply that we are estimating an "off-the-run" Treasury yield curve, one for which the liquidity of the included securities should be relatively uniform. The liquidity implicit in our curve should be regarded as adequate, though well short of the remarkable liquidity of on-the-run issues.

The outstanding maturities available for estimation are shown in Gürkaynak et al. (2006). These maturities were short (seven years or less) in the 1960s, but have subsequently lengthened. We report estimates of the yield curve at horizons that go as far out as possible without extrapolating far beyond the range of maturities that are actually outstanding on each date. Specifically, we report yield curve estimates out to seven years for the early part of the sample, extend them to 10 years on 16 August 1971, to 15 years on 15 November 1971, to 20 years on 2 July 1981, and to 30 years since 25 November 1985. Of course, with the estimated parameters from the NSS yield curve, one could compute yields and forward rates at any horizon; however, we would strongly recommend only focusing on those measures at the horizons for which outstanding securities were available for estimation.

At the very longest maturities, the yield curve consistently slopes down because of convexity and this can be captured by the second hump in the NSS curve. But because this is typically located at long horizons, it cannot be usefully identified in the very early part of our sample, when the longest maturity available was 15,10 , or even seven years. This leads us to impose restrictions on the estimation method earlier in our sample. Specifically, we use the original Nelson-Siegel specification for the period before 1980, that is we restrict

\footnotetext{
${ }^{7}$ To avoid an abrupt change to the sample, we allow their weights to linearly decay from 1 to 0 over the year ending on January 2, 1996.

${ }^{8}$ Some simple statistics on trading volume highlight just how different the on-the-run issues are from other Treasury issues. According to Sack and Elsasser (2004), the weekly turnover rate for off-the-run Treasury securities in 2003 (that is, weekly trading volume as a percent of outstanding debt) was about $22 \%$, while it was a remarkable $1400 \%$ for on-the-run issues.
} 
the parameter $\beta_{3}$ to be zero. This generates a better identified yield curve without compromising goodness of fit.

A final issue is whether to make adjustments for tax effects, as discussed by McCulloch (1975). The correct adjustment seems hard to determine, in part because Treasury securities are held by a wide range of investors with different tax brackets. Many Treasury investors, including pension funds, are exempt from taxes. Also, Treasuries provide a tax advantage for state and local taxes that depends on the state of residence of the investor. Given these considerations, we chose not to make adjustments for tax effects. Nevertheless, tax considerations may be important in some applications, in which case users might want to make tax adjustments to our smoothed yield curve.

\section{Results}

Using the above methodology, we estimate the U.S. Treasury yield curve from June 1961 to the present. As an example of the results, Fig. 1 shows the estimated yield curve on May 9, 2006. The solid line is the continuously compounded par-yield curve, the open circles are the actual quotes on all outstanding coupon securities included in the estimation, and the crosses are the predicted yields for those issues.

As can be seen, the yield curve does an impressive job fitting the entire cross-section of Treasury coupon issues with a function of only six parameters. The largest misses are for very short-term issues, which we attribute to the idiosyncratic nature of those securities, and for several securities in the two- to three-year maturity range that appear somewhat divorced from other yields on that day.

The success at fitting Treasury yields on this date is repeated throughout the sample. Fig. 2 shows the average absolute yield prediction error in different maturity buckets over time. As can be seen, all of the errors are generally quite small over the entire sample. The largest fitting errors tend to be seen at the longest maturities that are being fitted. It can also be seen in Fig. 2 that the fit of the yield curve has generally improved over time. One possible explanation of this fact is that the market has become more active and liquid, which has reduced pricing anomalies across various securities. ${ }^{9}$

Fig. 3 returns to the specific date considered in Fig. 1, only now showing the instantaneous forward rates and the zero-coupon yield curve. To assess the performance of the NSS method, it is useful to add some interpretation to the shape of the yield curve that day. At short horizons, forward rates and yields decline slightly, apparently reflecting market expectations for slight easing of monetary policy in 2007 and beyond. Beyond this range, both curves turn up, reflecting the normal upward-sloping pattern of the yield curve associated with term premia. However, the upward slope of the yield curve tapers off at long horizons and eventually turns down, and the forward curve turns down earlier and more sharply.

While the NSS specification is sufficiently rich to capture the shape of the yield curve associated with policy expectations and convexity, it is not so flexible as to be significantly influenced by the idiosyncratic behavior of a small number of securities. A useful example

\footnotetext{
${ }^{9}$ Under that interpretation, it is interesting to note that the fit of the estimation temporarily worsened slightly after the financial market turmoil in the fall of 1998. Fleming (2000) has suggested that Treasury securities may have become less connected to one another at that time because many of the arbitrage desks that ensure the close relationships across securities became less active.
} 


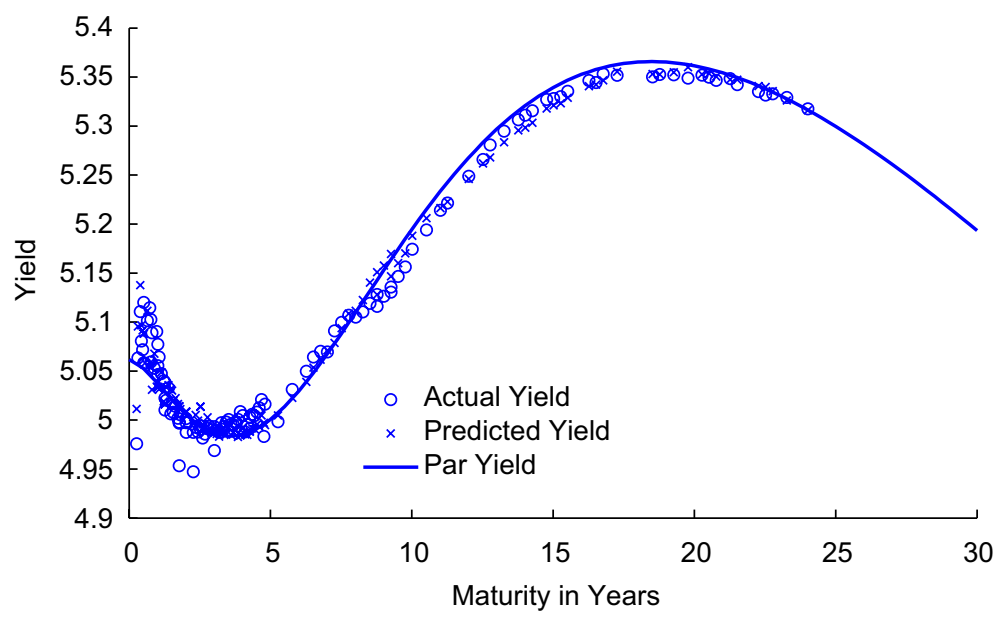

Fig. 1. Par-yield curve on May 9, 2006.

took place in the spring of 2005, when the markets reportedly became concerned that the supply of 10-year notes that were cheapest-to-deliver into the Chicago Board of Trade's Treasury futures contract was not sufficient to meet the required delivery (Whitehouse et al., 2005). As shown in Fig. 4, the market began to place a significant premium on the August 2012 note, which was cheapest-to-deliver into the September 2005 10-year futures contract. Other securities in the June and September deliverable basket also attracted a premium. Some fitting methods would capture this pattern with sizable swings in forward rates about seven years ahead that are unrelated to macroeconomic fundamentals. The NSS yield curve, however, is rigid enough that it does not give a dip at that particular maturity, but instead fits the general shape of the yields.

One issue that we confront when reviewing the historical yield curve estimates is that the estimated parameters demonstrate some instability, in that they sometimes jump discretely from one day to the next, often with little actual movement in underlying bond prices. Anderson and Sleath (1999) illustrate clearly that changing a single data point in the set of prices used to fit the NSS yield curve can produce a notable shift in parameters and also in fitted yields. This is a drawback of parameterized yield curves, and forward rates can be particularly affected. However, it is important to note that although these jumps in parameters can be large, the changes in predicted yields over most of the maturity range considered are quite muted. In effect, there is an identification issue and the estimation is arriving at fairly similar yield curve shapes over the most of the maturity range considered through different combinations of parameters. ${ }^{10}$ Despite this issue, the smoothness of the NSS yield curve, its ease of economic interpretation, and its relative insensitivity to

\footnotetext{
${ }^{10}$ For example, averaging over the days where the absolute change in $\beta_{0}$ was in the top percentile, the maximum absolute change in the zero-coupon yield across all maturities from one to 20 years was 10 basis points and the maximum absolute change in the instantaneous forward rate across all these maturities was 20 basis points. Meanwhile $\beta_{0}$, which is the asymptote of the instantaneous forward curve jumped by over 2 percentage points on all these days. Yields, and especially forward rates, were more sensitive to these parameter jumps at maturities beyond 20 years.
} 


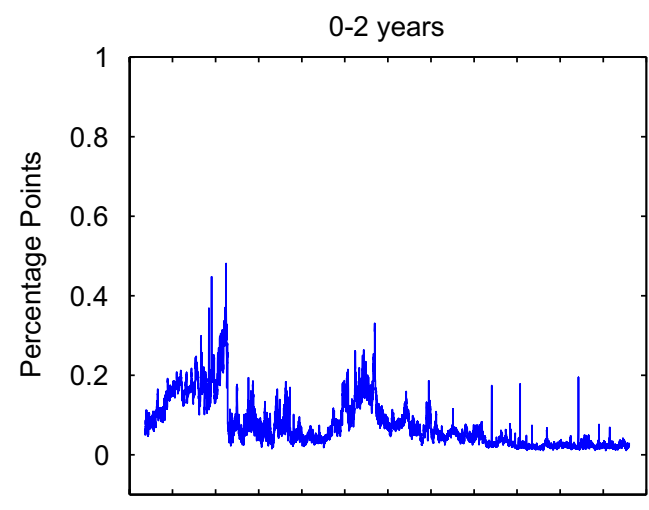

60646872768084889296000408

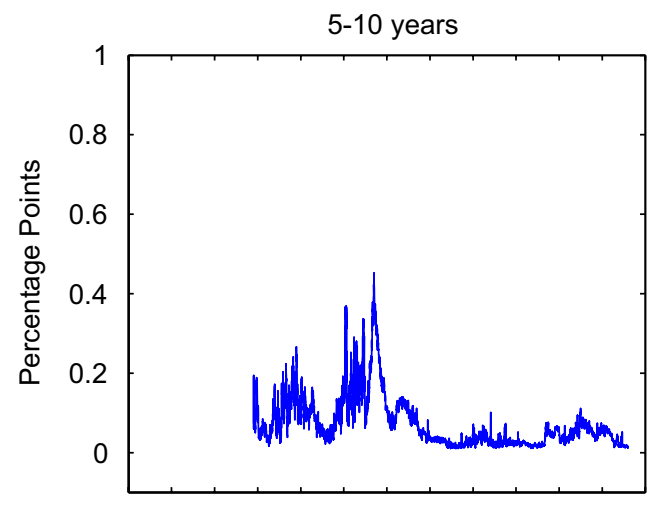

60646872768084889296000408

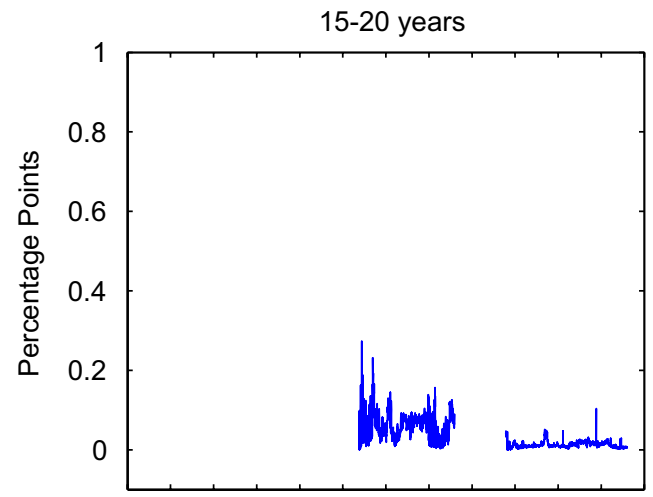

60646872768084889296000408

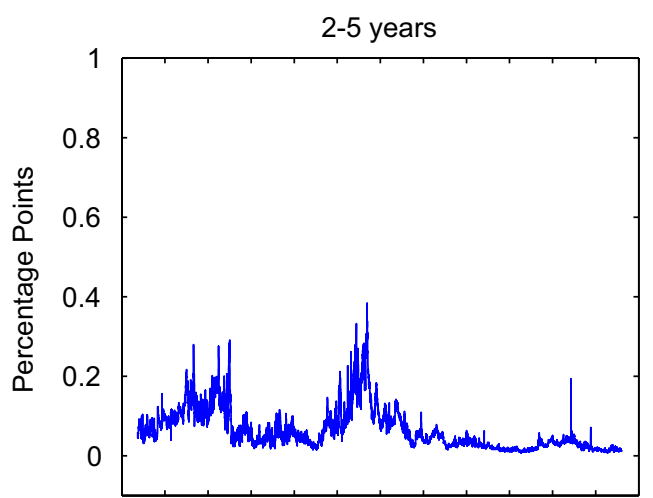

60646872768084889296000408
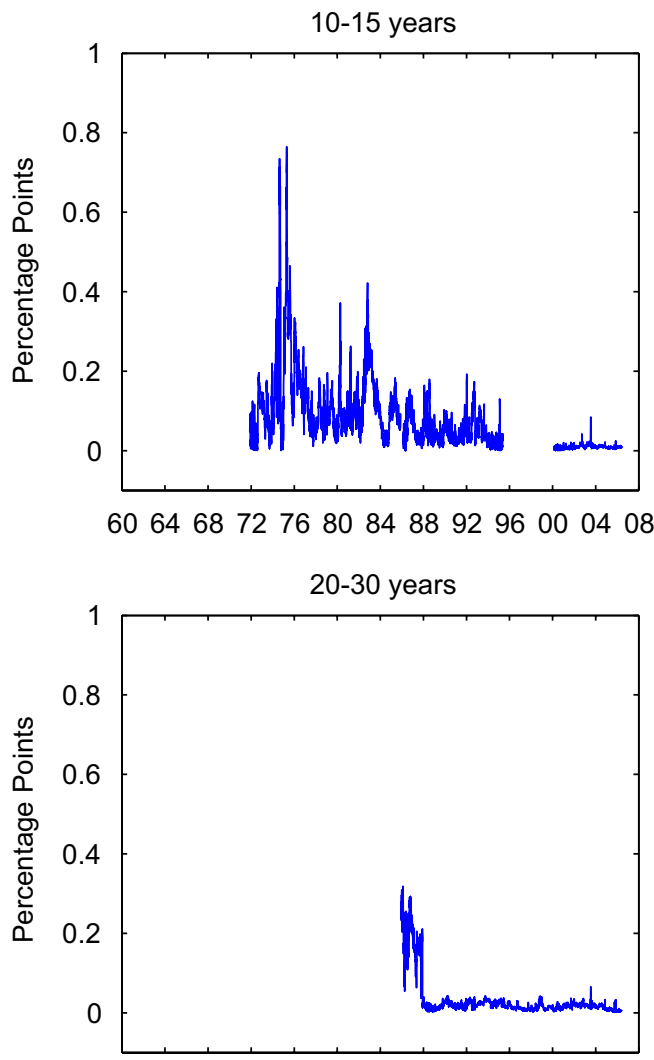

60646872768084889296000408

Fig. 2. Average absolute yield prediction errors by indicated maturity bin. 


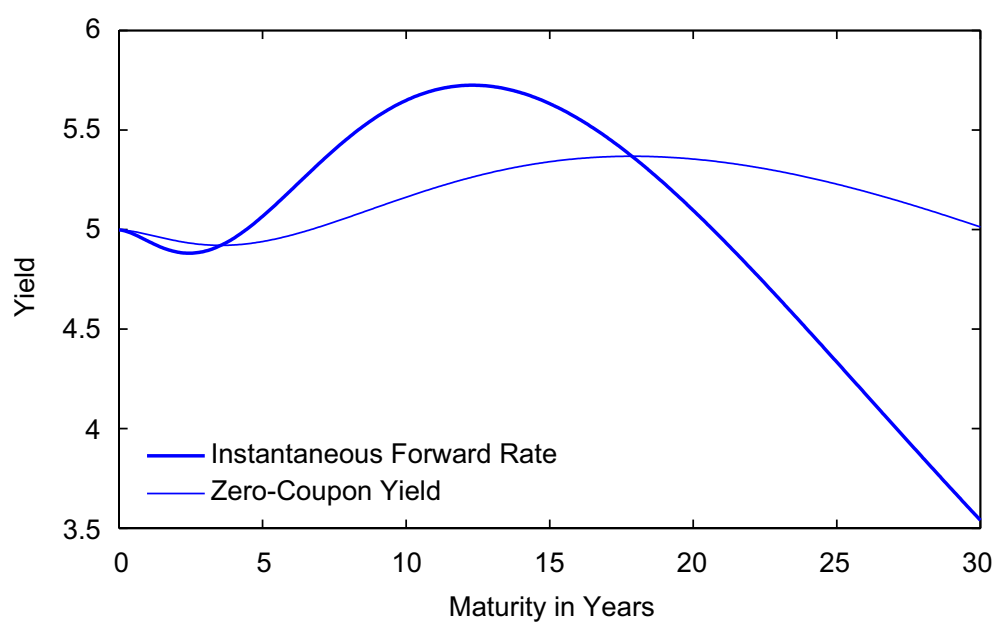

Fig. 3. Zero-coupon yield curve and forward rates on May 9, 2006.

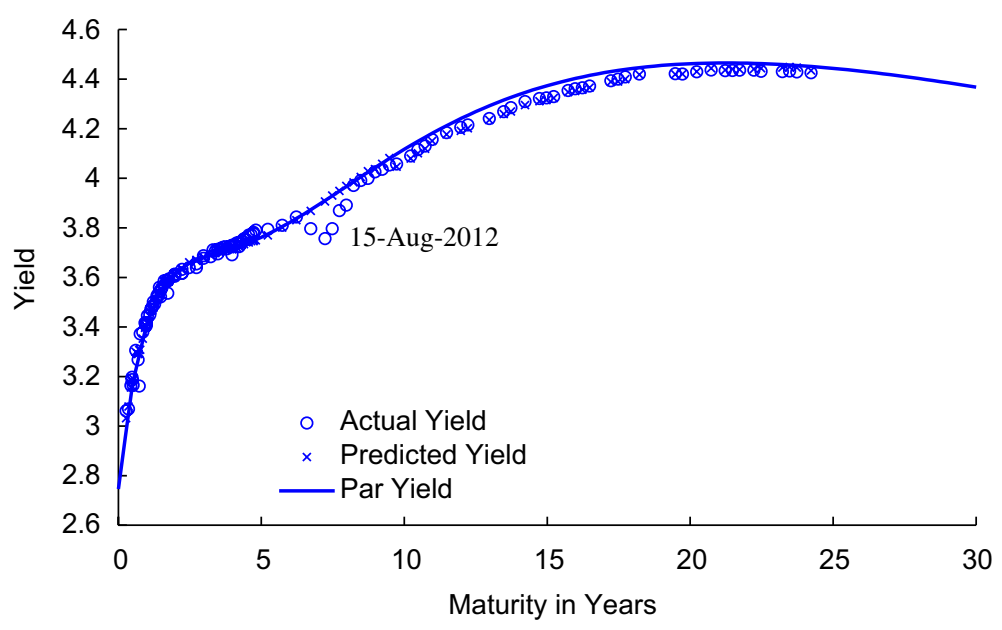

Fig. 4. Premium for the cheapest-to-deliver issue on May 24, 2005.

parameter shifts over a broad range of horizons leads us to nonetheless prefer the NSS curve for our purposes to alternatives such as splines. ${ }^{11}$

The appendix that accompanies this paper provides data on zero-coupon yields (continuously compounded), instantaneous forward rates (continuously compounded) and par yields (coupon-equivalent), for the full range of maturities that we consider at the daily frequency back to June 14, 1961. One-year par forward rates (coupon-equivalent) beginning one, four, and nine years ahead and the estimates of the parameters of the NSS

\footnotetext{
${ }^{11}$ The instability in parameters could in principle owe to the numerical optimization algorithm for minimizing the criterion function failing to find the global minimum on some days. However, the insensitivity of our results to starting values leads us to think that this is not the case.
} 
Table 1

Description of the series in the data appendix

\begin{tabular}{llll}
\hline Series & Compounding convention & Mnemonics & Maturities reported (max) \\
\hline Zero-coupon yield & Continuously compounded & SVENYXX & All integers 1-30 \\
Par yield & Coupon-equivalent & SVENPYXX & All integers 1-30 \\
Instantaneous forward rate & Continuously compounded & SVENFXX & All integers 1-30 \\
One-year forward rate & Coupon-equivalent & SVEN1FXX & 1,4 , and 9 \\
Parameters & N/A & BETA0 to TAU2 & N/A
\end{tabular}

Notes: XX in each case denotes the maturity in years. For example, SVENY10 denotes the 10-year zero-coupon yield. Maturities reported are limited before 1985 as described in the text. The one-year forward rates XX years hence denote the one-year forward rates beginning XX years hence. For example, SVEN1F09 is the one-year forward rate from nine to 10 years hence. The parameters are labeled BETA0, BETA1, BETA2, BETA3, TAU1, and TAU2, corresponding to the equations in the text. Note that the parameters BETA3 and TAU2 are restricted to zero in the earlier part of the sample, as discussed in the text.

yield curve are also included. The appendix is posted on the web at http://www. federalreserve.gov/pubs/feds/2006/200628/feds200628.xls and uses the mnemonics listed in Table 1 . We intend to update the data quarterly, as a resource for academic researchers and financial market practitioners.

\section{Synthetic treasury securities}

The yield curve can be used to construct a "synthetic" off-the-run Treasury security with any maturity date and coupon rate desired. Such securities can be useful for assessing the relative value of other securities.

The approach is straightforward. The estimated yield curve provides us with the value that investors place on a known, risk-free payment at any date in the future. Thus, for a hypothetical coupon rate and maturity date, we can compute the value of each payment on the security and sum them up to arrive at a predicted price of the synthetic security, which can then be converted to its yield. This represents the yield that one would expect on an off-the-run Treasury security with those exact payments.

This procedure can be used for computing a benchmark against which to measure spreads on various securities. For example, it could be applied to measure the credit risk spread for a corporate bond. Whereas most applications measure corporate spreads relative to individual Treasury securities, the payments and maturities of the two securities will differ some. By using a synthetic Treasury with identical payments, one eliminates any distortions coming from mismatched payments and the resulting differences in duration and convexity. Moreover, since it is an off-the-run synthetic Treasury security, it may have liquidity that is closer to that of the corporate bond than would an on-the-run issue.

Here we choose to demonstrate this technique by considering the liquidity premium for the on-the-run 10-year Treasury note. On-the-run Treasury issues were excluded from the estimation of the yield curve. As noted above, these securities typically trade at a premium to off-the-run Treasuries, as investors are willing to pay a higher price for the greater liquidity offered by these securities. Many market participants measure the on-the-run premia relative to the first or second off-the-run security, but those issues will have shorter duration. The difference in duration can distort the measure, especially when the Treasury yield curve is steep. 


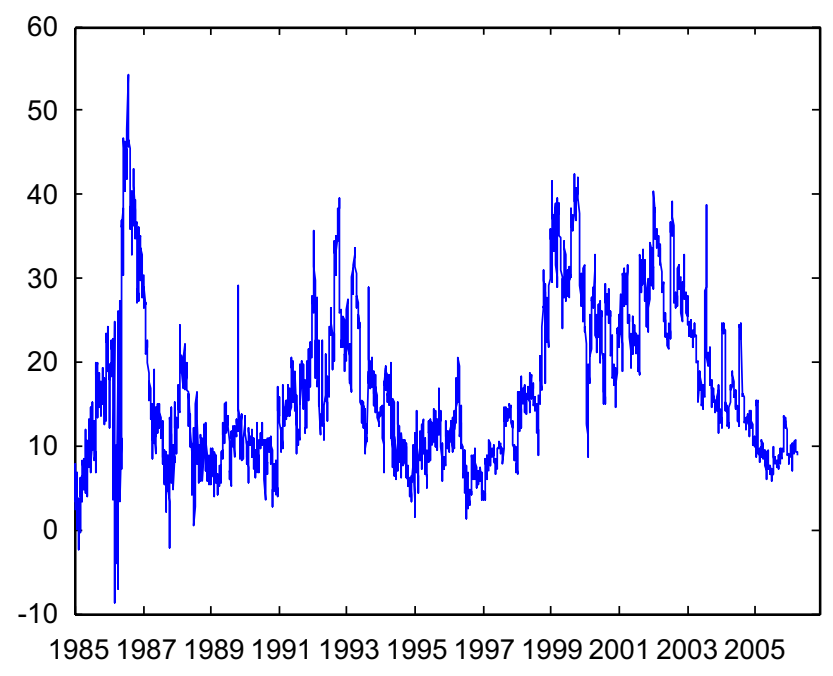

Fig. 5. Premium for the on-the-run 10-year Treasury note.

We instead measure the liquidity premium for an on-the-run issue by comparing it to a synthetic off-the-run Treasury security with the same coupon rate and maturity date. The resulting measure for the 10-year Treasury note is shown in Fig. 5 for the period since 1985. As can be seen, there is considerable variation in the measure at high frequency. In part, this reflects the auction pattern of the on-the-run premium: the premium tends to jump higher at the auction of a new security, when the liquidity advantage of the on-the-run issue will be realized for the longest time, and then diminishes gradually up to the auction of a new security. But there is also more gradual and persistent variation over time that is of interest. The liquidity premium appears to move up during periods of financial turmoil, including the stock market crash of 1987 and the seizing up of markets in the fall of 1998. Moreover, the premium remained relatively high from 2000 to 2002, a period during which the supply of on-the-run issues was curtailed. ${ }^{12}$ More recently, the premium has moved back to about 10 basis points, a level that appears relatively normal for tranquil periods.

The variation in this premium highlights a shortcoming of using the yields on on-the-run issues to measure the shape of the yield curve. Movements in those yields can be associated with changes in the liquidity premium, particularly around Treasury auctions. This is why we exclude these securities from our yield curve estimation. This concern also applies to the Treasury constant maturity series (reported in the Federal Reserve's H.15 release), which are estimated from a blend of on-the-run and off-the-run issues.

\section{Conclusion}

In this paper we have estimated the U.S. Treasury yield curve using a simple and parsimonious approach. The approach is quite effective at capturing the general shape of

\footnotetext{
${ }^{12}$ The on-the-run premium has been elevated at other times as well. Indeed, the largest premium under our measure occurred in 1986. While the source of that premium is unclear, it may have been driven in part by special demand for on-the-run securities from foreign investors.
} 
the yield curve while smoothing through the idiosyncratic variation in the yields on individual securities. As such, the results should prove useful for understanding the general macroeconomic and other factors that have broad effects on the shape of the yield curve. The estimated yield curve can be expressed in a variety of ways, including zero-coupon yields, par yields, and forward rates.

Our yield curve fills a void in the academic literature. To our knowledge, no estimated yield curve is available on a daily basis back to the early 1960s. The data set of Fama and Bliss (1987) (which has been updated) is monthly, and only provides estimates out to fiveyear maturities, while the data set of McCulloch and Kwon (1993) is also monthly and only provides estimates out to 10-year maturities. Our data set has the advantages of being available on a daily basis, extending back to 1961, providing estimates for all maturities that are feasible given the distribution of outstanding securities, and being updated on a regular basis. The full data set is available to be downloaded from http://www. federalreserve.gov/pubs/feds/2006/200628/feds200628.xls and will be updated quarterly.

\section{References}

Anderson, N., Sleath, J., 1999. New estimates of the U.K. real and nominal yield curves. Bank of England Quarterly Bulletin November, 384-392.

Duffee, G., 1996. Idiosyncratic variation of Treasury bill yields. Journal of Finance 51, 527-551.

Fama, E., Bliss, R.R., 1987. The Information in Long-Maturity Forward Rates. American Economic Review 77, 680-692.

Fisher, M., Nychka, D., Zervos, D., 1995. Fitting the term structure of interest rates with smoothing splines. Finance and Economics Discussion Series, 95-1.

Fleming, M.J., 2000. The benchmark U.S. Treasury market: recent performance and possible alternatives. Federal Reserve Bank of New York Economic Policy Review 6, 129-145.

Garbade, K.D., 2004. The institutionalization of Treasury note and bond auctions, 1970-75. Federal Reserve Bank of New York Economic Policy Review 10, 29-45.

Gürkaynak, R.S., Sack, B., Wright, J., 2006. The U.S. Treasury yield curve: 1961 to the present. FEDS Working Paper \#2006-28.

McCulloch, J.H., 1975. The tax-adjusted yield curve. Journal of Finance 30, 811-830.

McCulloch, J.H., 1990. U.S. term structure data, 1946-87. In: Handbook of Monetary Economics, vol. I, pp. 672-715.

McCulloch, J.H., Kwon, H.-C., 1993. U.S. term structure data, 1947-1991. Ohio State Working Paper \#93-6.

Nelson, C.R., Siegel, A.F., 1987. Parsimonious modeling of yield curves. Journal of Business 60, 473-489.

Sack, B., Elsasser, R., 2004. Treasury inflation-indexed debt: a review of the U.S. experience. Federal Reserve Bank of New York Economic Policy Review 10, 47-63.

Svensson, L.E.O., 1994. Estimating and interpreting forward rates: Sweden 1992-4. National Bureau of Economic Research Working Paper \#4871.

Waggoner, D., 1997. Spline methods for extracting interest rate curves from coupon bond Prices. Federal Reserve Bank of Atlanta Working Paper 97-10.

Whitehouse, M., Lucchetti, A., McKay, P.A., 2005. Short-bond shortage isn't over. Wall Street Journal. 